\begin{abstract}
Laboratory for Dosimetric and Radon Instruments Calibration which is a part of Central Laboratory for Radiological Protection (CLRP) in Warsaw is equipped with ${ }^{241} \mathrm{Am}$-Be neutron calibration source with activity of $185 \mathrm{GBq}$ since 1999. The capsule was mounted in the OB26 type shielding container. The control room is separated from the above source by a concrete wall of $0.5 \mathrm{~m}$ in thickness. The calibration hall is adjacent to one side of the office room. To comply with the requirements of the radiological protection system, the occupational exposure of persons that are working both in the office and control room needs to be assessed. Two methods were involved for ambient dose equivalent rate determination. The active instrument measurements (AIMs) performed with the Berthold LB6411 neutron probe and the Monte Carlo simulation method (MCS) based on MCNP5 code. These estimations were completed for five reference points. Additionally the $\gamma$ radiation component was measured by RSS131 ionisation chamber. An increased value of the ambient dose equivalent rate from neutrons was observed in two reference positions. The first observation was done in the control room while the second one in the office room. Expected individual dose equivalents were evaluated based on the results of the AIM and on the expected working time in particular reference points. The annual individual dose equivalent associated with calibration activities using mentioned neutron source was estimated at maximum $0.8 \mathrm{mSv}$.
\end{abstract}

Key words: occupational exposure • active instruments measurements • neutron source calibration

K. Szewczak ${ }^{\bowtie}$

Central Laboratory for Radiological Protection,

7 Konwaliowa Str., 03-194 Warsaw, Poland,

Tel.: +48 22811 0011, Fax: +48 228110016 ,

E-mail: szewczak@clor.waw.pl

\section{S. Jednorog}

Institute of Plasma Physics and Laser Microfusion, EURATOM Association,

23 Hery Str., 01-497 Warsaw, Poland

Received: 11 February 2014

Accepted: 21 July 2014

\section{Introduction}

Since the isotopic neutron sources have been approved by the International Standard Organization [1] as reference sources for the neutron radiological instruments calibration, the ${ }^{241} \mathrm{Am}-\mathrm{Be}$ neutron sources came to be most suitable for that purpose [2]. It happened mainly because of the long half-life of the americium [3, 4]. Typical activity of the ${ }^{241} \mathrm{Am}$ isotope used for that kind of source is $185 \mathrm{GBq}$. Two configurations of working position of the source are commonly used. The first option is when the source is located inside the biological shielding and the neutron beam is derived by the collimation channel when the source is pushed to working position. In the second option the source is pushed entirely from the container and the neutron beam is not collimated. From the radiological point of view the second concept is less safe and requires more complex radiological shields to be mounted in the calibration facility. In the first case the special attention should be paid to the radiological protection of persons that could be present in the space of the collimated neutron beam axis. Independently from the calibration facility configuration, the estimates of the occupational exposure of staff operating the source should be performed. The CLRP calibra- 


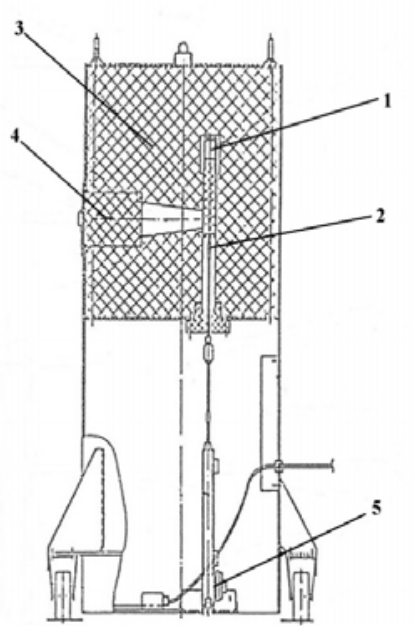

Fig. 1. The scheme of OB26 irradiator: (1) ${ }^{241} \mathrm{Am}-\mathrm{Be}$ neutron source in safe position, (2) lifting rod, (3) shielding material, (4) irradiation channel with sealing plug, (5) source moving mechanism.

\section{X.14}

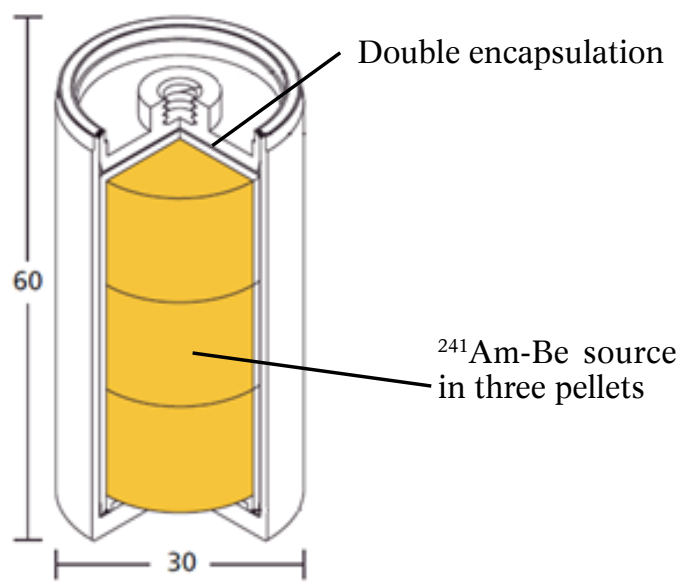

Fig. 2. The neutron source mounted in OB26 irradiator in CLRP (dimensions are in $\mathrm{mm}$ ).

tion facility was supported with ${ }^{241} \mathrm{Am}$-Be source in 1999. The source with $185 \mathrm{GBq}$ total activity of ${ }^{241} \mathrm{Am}$ is mounted in biological shielding of the OB26 irradiator [5], see Fig. 1. The source is double encapsulated in X14 cylindrical type capsule, see Fig. 2. This paper presents two methods of annual effective dose assessment for the operators who are involved in neutron survey calibration - Monte Carlo simulation (MCS) and active instrument measurements (AIMs). Then, both results are compared and discussed.

\section{Materials and methods}

Calculations and measurements of the occupational exposure were realised for two positions of the ${ }^{241} \mathrm{Am}$ -Be source. In the safe position (SP) the source is placed in the extreme upper part of the source channel, about $1.33 \mathrm{~m}$ above the floor. To achieve work position (WP) the source is moved down, to the level of the irradiation channel, i.e. $1.10 \mathrm{~m}$ above the floor.

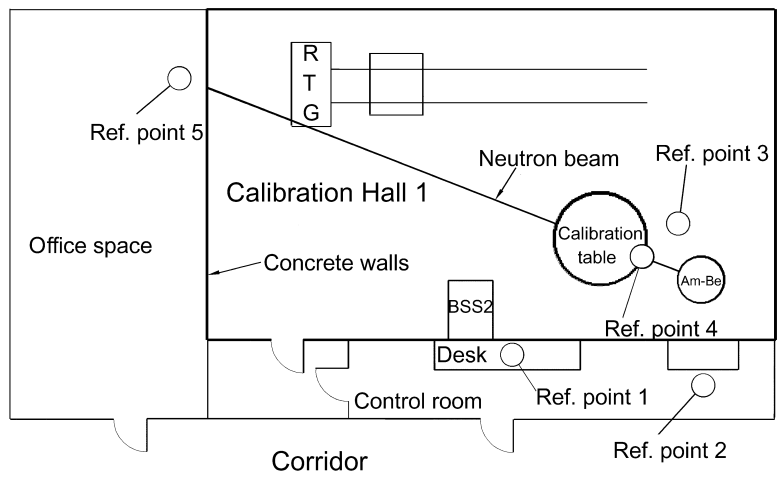

Fig. 3. Calibration hall geometry with main infrastructure elements and adjacent control room and office space.

The OB26 is mounted in the corner of the calibration hall, $1 \mathrm{~m}$ from the both walls. The dimensions of the hall are: $11.2 \times 7.5 \times 4.0 \mathrm{~m}$. Two working spaces are adjacent to the calibration hall. The control room is one of them and the office space is the second one. Both of them are separated from the calibration hall by a concrete wall of $0.5 \mathrm{~m}$ thickness. The ambient dose equivalent rate was assessed for five reference points (see Fig. 3): (1) on the desk in the control room, (2) in the corner of the control room, on the level equal to the source position, (3) $1 \mathrm{~m}$ from the source, on the surface at an angle of $45^{\circ}$ with the beam axis, (4) $1 \mathrm{~m}$ from the source at the beam axis and (5) in the office space, at the beam axis. During all AIM and MCS, the instruments and the virtual detector (MCNP tally F5) were placed $1.1 \mathrm{~m}$ above the floor.

\section{Monte Carlo simulations}

Monte Carlo simulations were realised using MCNP5 code [6] and ENDF/B-VI Release 8 cross section files. The material composition used for the OB26 was as proposed by the Mazrou [7]. The material composition of other elements included in the considered geometry was based on the compendium [8]. It was assumed that all infrastructure elements presented in the calibration hall were made of steel. The summary of materials composition used in the simulation was presented in Table 1 . The geometry of the calibration hall includes the main infrastructure elements as RTG calibration stand, Beta Secondary Standard 2 stand and the neutron calibration table. The above geometry is presented in Fig. 3. The initial neutron energy spectrum emitted from the Am-Be source was described in the input file by 'SI' and 'SD' cards using data from International Standard [1]. Tally F5 (flux at point detector) multiplied by the fluence-to-ambient dose equivalent conversion coefficients based on the ICRP Publication 74 was used.

\section{Active instrument measurements}

Two independent measurements were performed for assessment of ambient dose equivalent rate from neutron and $\gamma$ components. For neutron measurements the Berthold LB123 UMo instrument with 
Table 1. Materials composition used for MCS

\begin{tabular}{|c|c|c|c|c|c|c|c|c|c|}
\hline \multirow{2}{*}{$\begin{array}{l}\text { Geometry } \\
\text { element }\end{array}$} & \multicolumn{2}{|c|}{ Am-Be source } & \multirow{2}{*}{ Air } & \multicolumn{4}{|c|}{ OB26 container } & \multirow{2}{*}{$\begin{array}{l}\text { Concrete } \\
\text { walls }\end{array}$} & \multirow{2}{*}{$\begin{array}{l}\text { Infrastruc- } \\
\text { ture }\end{array}$} \\
\hline & $\begin{array}{c}\text { Active } \\
\text { material }\end{array}$ & $\begin{array}{l}\text { Encapsula- } \\
\text { tion }\end{array}$ & & $\begin{array}{l}\text { Polyethyl- } \\
\text { ene }\end{array}$ & Lead & Cadmium & Steel & & \\
\hline$\overline{\mathrm{H}}$ & & & & 14.30 & & & & 11.70 & \\
\hline $\mathrm{C}$ & & & 0.01 & 85.70 & & & & & \\
\hline $\mathrm{N}$ & & & 75.53 & & & & & & \\
\hline $\mathrm{O}$ & 1.00 & & 23.18 & & & & & 60.82 & \\
\hline $\mathrm{Si}$ & & & & & & & & 27.48 & \\
\hline $\mathrm{Be}$ & 83.54 & & & & & & & & \\
\hline $\mathrm{Am}$ & 15.46 & & & & & & & & \\
\hline $\mathrm{Cr}$ & & 20.30 & & & & & 20.30 & & 20.30 \\
\hline $\mathrm{Mn}$ & & 2.01 & & & & & 2.01 & & 2.01 \\
\hline $\mathrm{Fe}$ & & 67.79 & & & & & 67.79 & & 67.79 \\
\hline $\mathrm{Ni}$ & & 9.90 & & & & & 9.90 & & 9.90 \\
\hline $\mathrm{Pb}$ & & & & & 100 & & & & \\
\hline $\mathrm{Cd}$ & & & & & & 100 & & & \\
\hline $\mathrm{Ar}$ & & & 1.28 & & & & & & \\
\hline
\end{tabular}

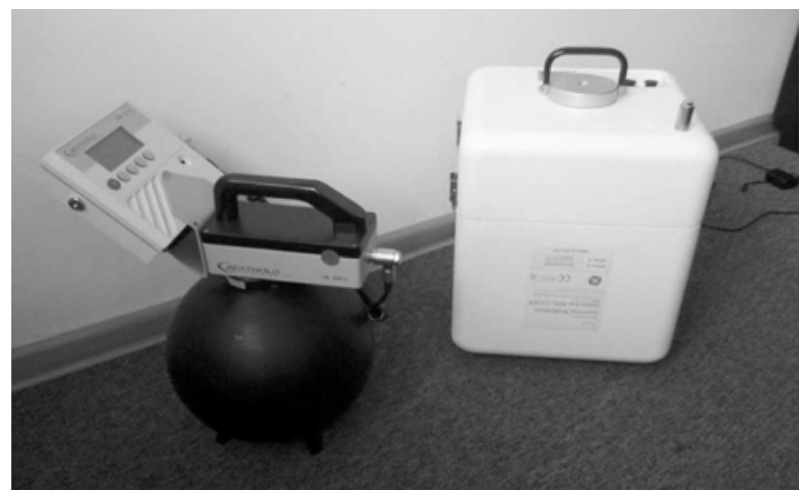

Fig. 4. Instruments used for AIM. The Berthold LB123 UMo with LB6411 neutron tube on the left and RSS131 ionisation chamber on the right.

LB6411 neutron tube was involved (see Fig. 4). The raw measurements $(\mathrm{M})$ were done in 'CPS' mode during which the information about uncertainty $(\mathrm{u}(\mathrm{M})[\%])$ is provided. For each reference point, the computed calibration factor, CCF was obtained by multiplying the normalised neutron flux spectrum, generated by MC simulation (see Figs. 5-8), and instrument calibration factor based on manufacturer characterisation [9] (see Fig. 9). For the purpose of multiplication, the spectra and the factor function were divided into 175 energy bins from $10^{-9}$ to $11 \mathrm{MeV}$. Calculated values of CCF's are given in Table 2.

Final values of neutron $\dot{H}^{*}(10)$ were derived from AIM according to the following equation:

$$
\dot{\mathrm{H}}^{*}(10)\left[\frac{\mu \mathrm{Sv}}{\mathrm{h}}\right]=\mathrm{M}[\mathrm{cps}] \cdot \mathrm{CCF}\left[\frac{\mu \mathrm{Sv}}{\mathrm{h} \cdot \mathrm{cps}}\right]
$$

where: $\quad \mathrm{CCF}=\sum_{i=1}^{175} \mathrm{CF}\left(E_{i}\right) \cdot \Phi_{n o r}\left(E_{i}\right)$

The detection limit (DL) for AIM (neutron) was determined according to the equation:

$$
\mathrm{DL}=\left(\overline{\mathrm{M}_{\mathrm{B}}}+3 \sigma\right) \cdot \mathrm{CF}_{\mathrm{Am}-\mathrm{Be}}
$$

where $M_{B}$ is the mean value from 20 background measurements in CPS performed in time of $1000 \mathrm{~s}, \sigma$ is a standard deviation of $\mathrm{M}_{\mathrm{B}}$ measurements, $\mathrm{CF}_{\mathrm{Am}-\mathrm{Be}}$ is an

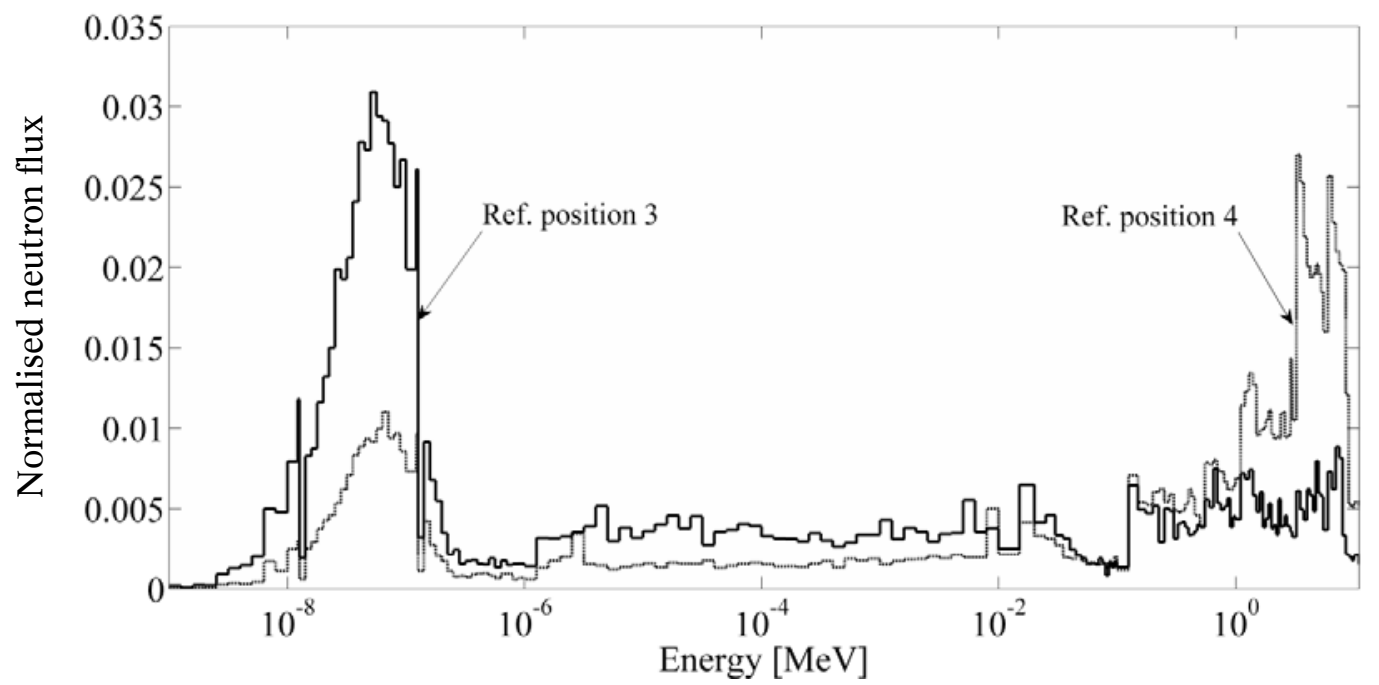

Fig. 5. Normalised neutron flux spectra at reference points 3 and 4 with source at work position. 


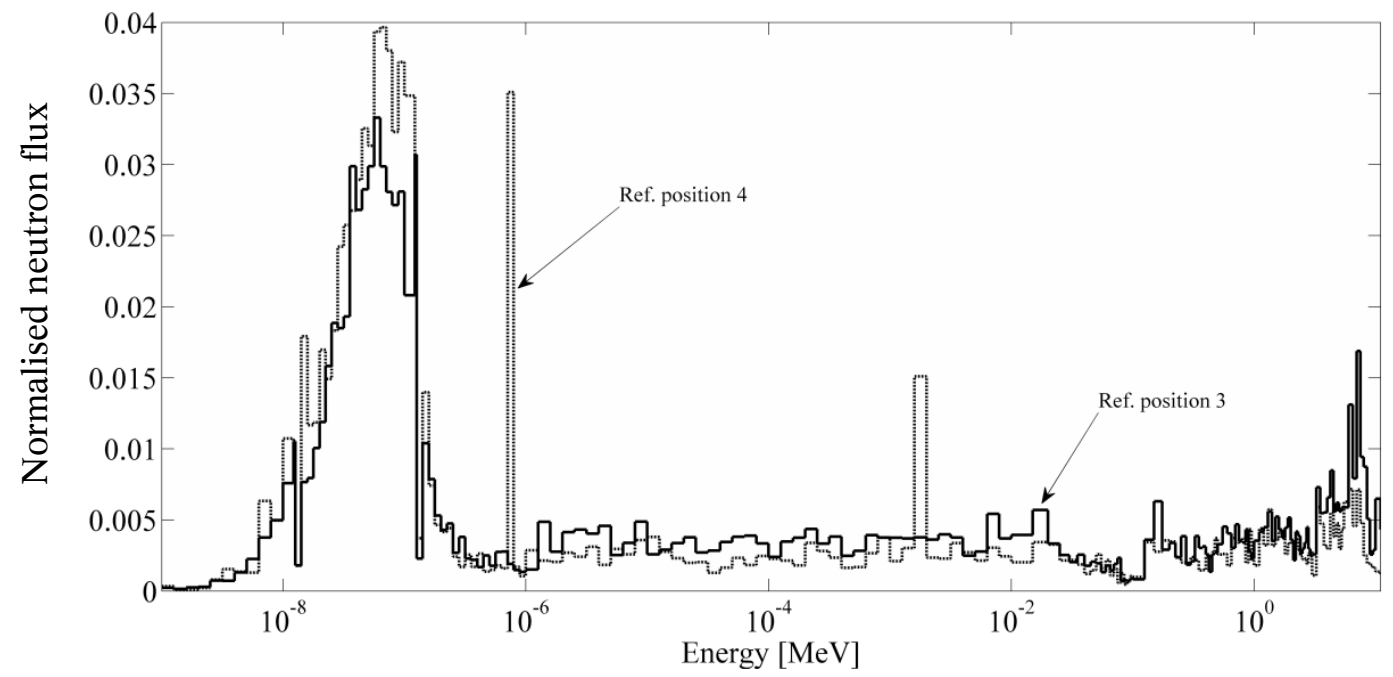

Fig. 6. Normalised neutron flux spectra at reference points 3 and 4 with source at safe position.

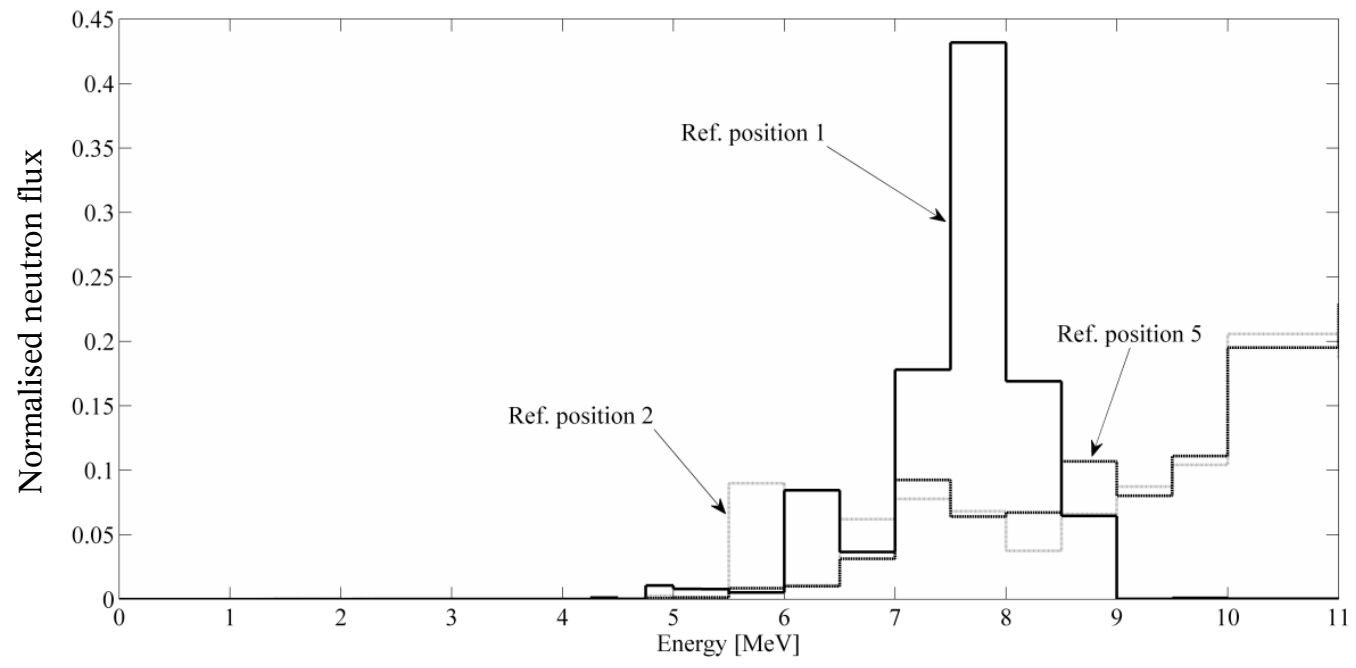

Fig. 7. Normalised neutron flux spectra at reference points 1,2 and 5 with source at safe position.

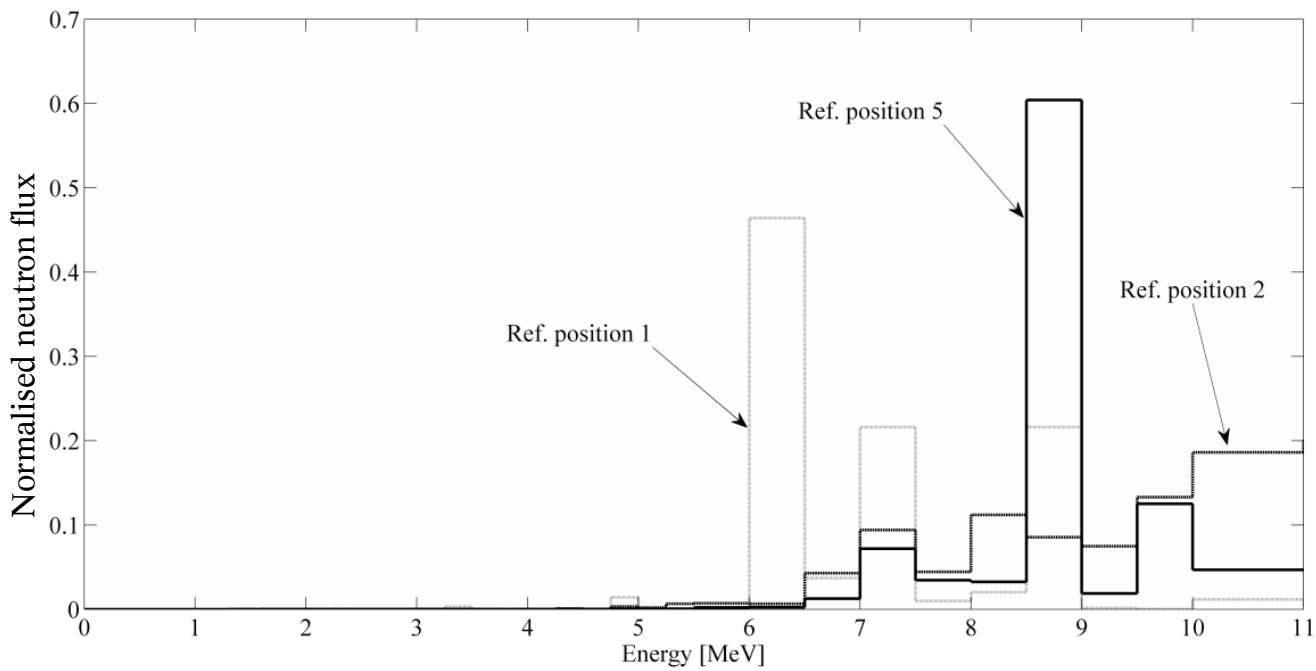

Fig. 8. Normalised neutron flux spectra at reference points 1, 2 and 5 with source at work position. 


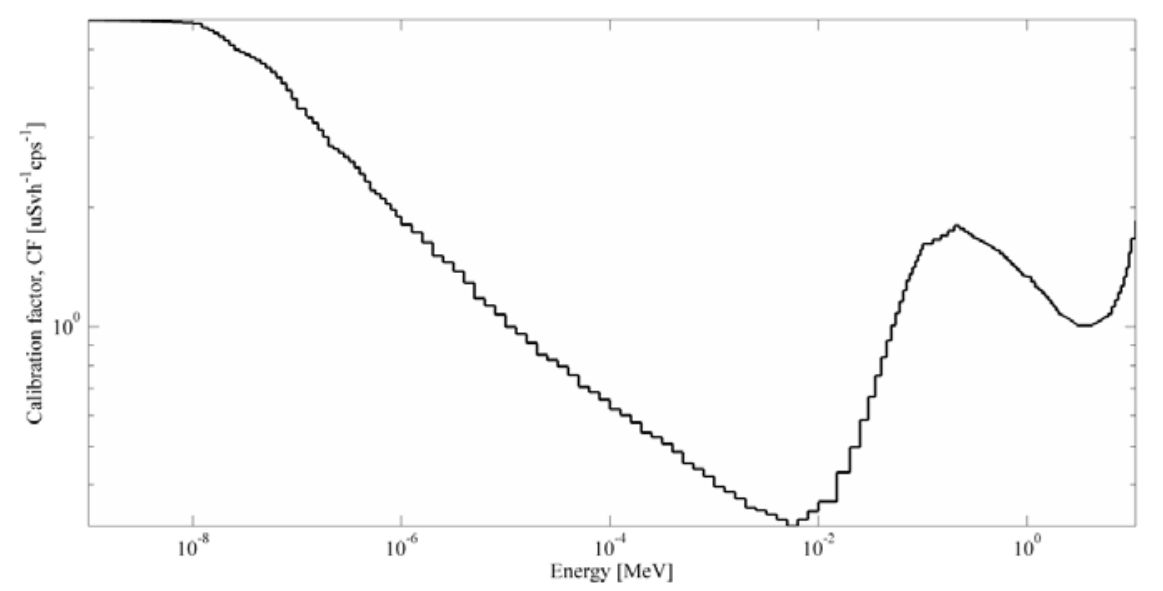

Fig. 9. Calibration factor values depending on the incident neutrons energy for Berthold LB123 UMo with LB6411 neutron tube.

Table 2. Ambient dose equivalent rate $[\mu \mathrm{Sv} / \mathrm{h}]$ obtained from AIM and MCS for neutron component

\begin{tabular}{lllll}
\hline \multicolumn{1}{c}{ Reference position no. } & 1 & 2 & 3 & 4 \\
\\
\hline
\end{tabular}

${ }^{a}$ symbol '-' means that the calculated value was less than 0.01 .

instrument calibration factor for neutrons emitted by ISO ${ }^{241} \mathrm{Am}$-Be source [1] and equal to 1.21 according to the manufacturer specification [9].

For the $\gamma$ component measurements, the high sensitivity ionisation chamber Reuter-Stokes RSS131 was used (see Fig. 4). The sensitive part of the instrument is $8.6-\mathrm{L}$ steel, high pressure spherical ionisation chamber, insensitive for neutrons by using a ultra-high purity argon as a working gas. The chamber was calibrated using ${ }^{241} \mathrm{Am}$ source at Laboratory of Dosemeters and Radon Devices Calibration (holding the accreditation of the Polish Center for Accreditation) and the calibration factor was implemented into the chamber software.

\section{Results}

Results of the AIM and MCS together with CCF values and the total combined uncertainties (U) for the neutron component are presented in Table 2 . It can be seen that the readings of neutron AIM strongly depend on the neutron energy, e.g. the values of CCF for SP change more than twice for different reference points - from 1.46 at reference position 2 to 3.12 at reference position 4. The results from MCS show that outside the calibration hall the component of low-energy neutrons is too small comparing with the high-energy one to be noticeable in the simulated spectrum. This is due to low neutrons emission from the source $\left(1.1 \times 10^{7} \mathrm{n} / \mathrm{s}\right)$ and in fact that macroscopic cross section for neutrons with energy of $5 \mathrm{MeV}$ interacting in concrete is about five time smaller than for neutrons with the energy in order of $\mathrm{keV}[10]$.

Neutron ambient dose equivalent rate, measured at the reference point 4 (in the beam line, $1 \mathrm{~m}$ from the source) was equal to $175.1 \pm 4.1 \mu \mathrm{Sv} / \mathrm{h}$ in WP. This is in perfect agreement with the value calculated by MCS. The value for the reference point 5 
Table 3. Ambient dose equivalent rate $[\mu \mathrm{Sv} / \mathrm{h}]$ obtained from AIM for $\gamma$ component

\begin{tabular}{lccccc}
\hline \multicolumn{1}{c}{ Reference position no. } & 1 & 2 & 3 & 4 & 5 \\
\hline & \multicolumn{5}{c}{ Save position } \\
AIM $(\gamma)[\mu \mathrm{Sv} / \mathrm{h}]$ & 0.12 & 0.23 & 0.93 & 0.97 & 0.10 \\
U $(\mathrm{AIM})$ & 0.01 & 0.02 & 0.05 & 0.05 & 0.01 \\
$\mathrm{U}(\mathrm{AIM})[\%]$ & 8.30 & 8.70 & 5.40 & 5.20 & 10.0 \\
& & Work position & & \\
$\mathrm{AIM}(\gamma)[\mu \mathrm{Sv} / \mathrm{h}]$ & 0.12 & 0.27 & 1.12 & 5.32 & 0.10 \\
$\mathrm{U}(\mathrm{AIM})$ & 0.01 & 0.02 & 0.06 & 0.25 & 0.01 \\
$\mathrm{U}(\mathrm{AIM})[\%]$ & 8.30 & 7.40 & 5.40 & 4.80 & 10.0 \\
\hline
\end{tabular}

(office space, behind the wall, in the beam line) was quite low of $0.07 \pm 0.02 \mu \mathrm{Sv} / \mathrm{h}$. Therefore, it was not possible to perform the MCS for this position in reasonable time.

All $H^{*}(10)$ rate values measured at the point 1 (desk in the control room), both for SP and WP, were below the detection limit DL for neutron AIM, which was assessed to be of about $0.02 \mu \mathrm{Sv} / \mathrm{h}$. The significant increase of the neutron radiation was observed in the corner of the control room (reference point 2) where the values of $\mathrm{H}^{*}(10)$ rate reached $0.51 \mu \mathrm{Sv} / \mathrm{h}$ for SP and $0.57 \mu \mathrm{Sv} / \mathrm{h}$ for WP. It is worth to notice, that the values for SP and WP are very similar. Also the values measured at the point 3 (in the calibration hall, $45^{\circ}$ from the beam line) do not change much with the change of the source position (from $7.11 \mu \mathrm{Sv} / \mathrm{h}$ in SP to $9.90 \mu \mathrm{Sv} / \mathrm{h}$ in WP). In this case, the increase, observed when the source was moved to the WP is partly associated with scattered neutrons. In SP, the neutron $\mathrm{H}^{*}(10)$ rate in the beam line (point 4 ) is very similar to those in the point 3. It can be, therefore, concluded that the neutron leak only slightly depends on the source position. In SP, neutrons are emitted to the front and both sides of the irradiator. The back side has not been investigated.

As mentioned above, the good agreement between measured and calculated values of neutron $\mathrm{H}^{*}$ (10) rate was obtained for WP at reference point 4. At other positions, considered here, the results from MCS were much lower than the AIM values. For SP, the result of MCS at point 3 was more than seven times lower than the result from AIM. This clearly shows that available information on the irradiator materials and geometry is not sufficient for reliable calculations.

It was also showed in the Table 3 that the contribution from the $\gamma$ radiation might by practically neglected during dose equivalent estimation. The contribution of $\gamma$ radiation in the calibration field constituted $3.0 \%$ of total $\mathrm{H}^{*}(10)$. It is with good agreement with value $(2.7 \%)$ calculated based on the results presented by Murata [11]. The contribution is less than $5.0 \%$ that gives the evidence that materials surrounding the source are equivalent to $1 \mathrm{~mm}$ of lead [1] and that the registered $\gamma$ radiation comes from de-excitation of ${ }^{12} \mathrm{C}^{*}(\gamma$ energy $-4.4 \mathrm{MeV})$ nucleus produced in the ${ }^{9} \mathrm{Be}(\alpha, n)$ reaction.

For the purpose of individual dose equivalent estimation it was assumed that any particular person during one working day can stay only $1 \mathrm{~h}$ in a distance not less than $0.5 \mathrm{~m}$ from the source surface and $6 \mathrm{~h}$ in the control room, respectively. Taking into consideration the value of the annual working time was estimated, that the maximum annual individual dose and equivalent does not exceed $0.8 \mathrm{mSv}$. It have also been estimated that the annual individual dose equivalent for the persons staying in the office space will not increase by more than $0.05 \mathrm{mSv}$ in result of using the neutron source.

\section{Conclusions}

- The presented results show that the working with the above mentioned calibration source only slightly contributes to the total annual dose of the Laboratory personnel.

- Good agreement between AIM and MCS was obtained for the reference measurements point in the beam line, at relatively high ambient dose equivalent rate. On the rest of the cases the results from MCS were always under the AIM results.

- The $\gamma$ radiation contribution can be neglected during dose equivalent estimation.

- As a result of performed investigation, it was decided not to implement the passive neutron individual dose monitoring for the Laboratory personnel.

\section{References}

1. International Organization for Standardization (2001). Reference neutron radiations, part 1: Characteristics and methods of production. Geneva, Switzerland. (ISO 8529-1).

2. Jozefowicz, K., Golnik, N., \& Zielczynski, M. (2004). Standard fields of old neutron sources - parameters and traceability. Radiat. Prot. Dosim., 110(1/4), 107-110.

3. Jozefowicz, K., Golnik, N., Tulik, P., \& Zielczynski, M. (2007). Radionuclide neutron sources in calibration laboratory - neutron and gamma doses and their changes in time. Radiat. Prot. Dosim., 126(1/4), 134-137.

4. Schuhmacher, H. (2004). Neutron calibration facilities. Radiat. Prot. Dosim., 110(1/4), 33-42.

5. Mazrou, H., Sidahmed, T., \& Allab, M. (2010). Monte Carlo investigation of radiation beam quality of the CRNA neutron irradiator for calibration purposes. Appl. Radiat. Isot., 68(10), 1915-1921.

6. X-5 Monte Carlo Team. (2003). MCNP - A General Monte Carlo N-Particle Transport Code. Version 5. Volume I: Overview and theory. Los Alamos: Los Alamos National Laboratory. 
7. Mazrou, H., Sidahmed, T., \& Allab, M. (2010). Neutron field characterisation of the ob26 crna irradiator in view of its use for calibration purposes. Radiat. Prot. Dosim., 141(2), 114-126.

8. McConn Jr, R. J., Gesh, C. J., Pagh, R. T., Rucker, R. A., \& Williams III, R. G. (2011). Compendium of material composition data for radiation transport modeling - radiation portal monitor project. Washington: Pacific Northwest National Laboratory Richland.
9. Berthold Technologies. (1996). Neutron probe LB6411 - operating manual. Bad Wildbag, Germany.

10. Blizard, E. P., \& Miller, J. M. (1958). Radiation attenuation characteristics of structural concrete. Oak Ridge: Oak Ridge National Laboratory. (ORNL-2193).

11. Murata, I., Tsuda, I., Nakamura, R., Nakayama, S., Matsumoto, M., \& Miyamaru, H. (2014). Neutron and gamma-ray source-term characterization of $\mathrm{AmBe}$ sources in Osaka University. Progress in Nuclear Science and Technology, 4, 345-348. 